\title{
Review article: New directions in medical education related to anesthesiology and perioperative medicine
}

\section{Article de synthèse: Nouvelles orientations en formation médicale liées à l'anesthésiologie et à la médecine périopératoire}

\author{
M. Dylan Bould, MB ChB • Viren N. Naik, MD • \\ Stanley J. Hamstra, PhD
}

Received: 9 December 2010/ Accepted: 15 November 2011/Published online: 10 December 2011

(c) Canadian Anesthesiologists' Society 2011

\begin{abstract}
Purpose We aim to provide a broad overview of current key issues in anesthesiology education to encourage both "clinician teachers" and "clinician educators" in academic health centres to consider how medical educational theory can inform their own practice.

Principal findings Evolving contextual issues, such as work-hour reform and the patient safety movement, necessitate innovative approaches to anesthesiology education. There is a substantial amount of relevant literature from other disciplines, such as sociology, psychology, and human factors research, using methodologies that are often unfamiliar to most clinicians. Recurring themes include the increasing use of simulation-based education, the importance of faculty development, challenges in teaching and assessing the non-medical expert roles, and the promise of team training and interprofessional education. Interdisciplinary collaborations are likely key to answering pressing questions in anesthesiology education, and a greater understanding of qualitative and mixed methods research
\end{abstract}

M. D. Bould, MB ChB · V. N. Naik, MD

Department of Anesthesia, Faculty of Medicine, University of Ottawa, Ottawa, ON, Canada

M. D. Bould, MB ChB - V. N. Naik, MD - S. J. Hamstra, PhD Academy for Innovation in Medical Education, Faculty of Medicine, University of Ottawa, Ottawa, ON, Canada

S. J. Hamstra, PhD

Departments of Medicine, Surgery and Anesthesia, Faculty

of Medicine, University of Ottawa, Ottawa, ON, Canada

M. D. Bould, MB ChB (ه)

Department of Anesthesiology, Children's Hospital of Eastern

Ontario, 401 Smyth Road, Ottawa, ON, Canada

e-mail: dbould@cheo.on.ca will allow a broader range of questions to be answered. Simulation offers the opportunity to learn from failures without exposing patients to risk and brings the challenge of integrating innovations into existing curricula. Interprofessional education allows learning in the teams that will work together; even so, it needs to be prioritized to overcome logistical barriers. The challenges of introducing a competency-based curriculum have resulted in hybrid systems where elements of competency-based medical education have been combined with traditional apprenticeship curricula. The value of faculty development to encourage even simple measures, such as establishing learning objectives and discussing these with trainees, cannot be over-emphasized. Key issues in assessment include the need to evaluate multiple levels of performance in a cohesive system of assessment and the need to identify the unintended consequences of assessment.

Conclusions We have identified a number of key themes and challenges for anesthesiology education. This discussion will continue in greater depth in individual articles in this issue so as to promote further interest in a growing body of literature that is relevant to anesthesiology education.

\section{Résumé}

Objectif Notre objectif est de proposer un vaste aperçu des questions clés actuelles en matière de formation en anesthésiologie, afin d'encourager les "enseignants cliniciens» et les «éducateurs cliniciens» dans les centres de santé universitaires à réfléchir à la façon dont la théorie de la formation médicale peut bénéficier à leur propre pratique.

Constatations principales Certaines questions contextuelles en perpétuelle évolution, comme par exemple la réforme des heures de travail et le mouvement pour 
promouvoir la sécurité des patients, requièrent la mise en place d'approches innovantes dans la formation en anesthésiologie. La littérature pertinente d'autres disciplines telles que la sociologie, la psychologie et la recherche sur les facteurs humains est abondante, et elle utilise des méthodologies souvent peu connues de la plupart des cliniciens. Parmi les thèmes récurrents, citons le recours de plus en plus fréquent à la formation par simulation, l'importance du développement pour le corps professoral, les défis en enseignement et dans l'évaluation $d u$ rôle des experts non médicaux, ainsi que la promesse d'une formation en équipe et d'une formation interprofessionnelle. Il est probable que les collaborations interdisciplinaires sont un elément essentiel pour répondre aux questions urgentes liées à la formation en anesthésiologie, et une meilleure compréhension des recherches fondées sur des méthodes qualitatives et mixtes permettra de répondre à un éventail plus large de questions. La simulation offre la possibilité d'apprendre de ses échecs sans exposer un patient à des risques, et elle apporte également le défi d'intégrer les innovations dans les programmes de cours existants. Grâce à la formation interprofessionnelle, l'apprentissage se fait au sein d'équipes qui travailleront ensemble; ce type de formation a tout de même besoin d'être priorisée afin de surmonter les obstacles logistiques. Les défis liés à l'introduction d'un programme de cours fondé sur les compétences ont donné naissance à des systèmes hybrides combinant divers eléments de la formation médicale fondée sur les compétences à un programme d'apprentissage conventionnel. On ne peut que souligner une fois de plus l'intérêt de promouvoir le développement pour le corps professoral; cette approche permet d'encourager même les mesures les plus simples, telles que la création d'objectifs d'apprentissage et le fait d'en discuter avec les personnes en formation. Parmi les questions clés dans l'évaluation, citons le besoin d'évaluer plusieurs niveaux de performance dans un système cohérent d'évaluation et le besoin d'identifier les conséquences non prévues d'une telle évaluation.

Conclusion Nous avons identifié plusieurs thèmes et défis clés de la formation en anesthésiologie. Cette discussion sera approfondie dans le cadre d'articles individuels dans ce numéro afin de susciter l'intérêt pour un corpus croissant de littérature pertinente à la formation en anesthésiologie.

Faculty involvement in medical education is intrinsic to working in an academic health centre. This involvement ranges from the role of the "clinician-teacher", where informal teaching and assessment of learners may predominate, to the role of the "clinician-educator", where development of curricula, administration of training programs, and scholarship in medical education might be involved. Education has been described as one of the "three legs" of academic medicine along with research and clinical work. Its importance is self-evident and described well by this metaphor: as research is necessary for the creation of new knowledge, effective education is essential to generate new doctors; without it, the three-legged stool would collapse. In this paper, we argue that evolving changes to complex healthcare systems demand innovative approaches to effective medical education.

Although a considerable volume of education-related research is published in the anesthesiology literature, relevant reports of original investigations in education research often appear in many other specialty journals, which can hinder access for many teachers and educators. Furthermore, literature on educational theory and broader contextual issues is most likely published in the education and social sciences literature. Consequently, academic anesthesiologists may be less familiar with current trends in education science than with trends in clinical research. ${ }^{1}$

The aim of this review is to provide an overview of the literature pertaining to education in anesthesiology and relevant to perioperative medicine and critical care and pain that will be of interest to clinician-teachers and education specialists alike. Our aim is to stimulate discussion rather than to provide definitive answers, as in an overview of such a large topic, only a selected number of issues can be addressed. We will highlight issues of both current and future relevance to perioperative and critical care specialties with an overall goal of linking them to the broader context in medical education. A number of issues discussed in this article will be explored in greater detail in other articles appearing within this special theme issue.

In this review, we examine topics considered to be at the cutting edge of anesthesiology education and "hot topics" in medical education that are under-reported in the anesthesiology literature. Where possible, we have cited highquality review articles published within the past five years so readers can easily reference further introductory reading. In the first part of this review, we consider relevant contextual issues from outside the medical education literature; we highlight the multi-disciplinary nature of medical education, and we consider the research methodologies that underpin educational theory. In the second part of this review, we address educational theory relating to curricula, teaching and learning, and assessment in anesthesiology. Other articles in this issue elaborate further on these topics. They broadly follow the outline described above and allow further exploration of recurring educational themes, such as the use of simulation-based education, interprofessional education, and the non-medical expert roles as defined by CanMEDS. $^{2}$ The theme of anesthesiology education in this 
issue is intended for an international audience, although the focus of the final paper is on current challenges in anesthesiology education within the Canadian context.

\section{Why should we innovate in medical education?}

"He that will not apply new remedies must expect new evils; for time is the greatest innovator." Francis Bacon, Of Innovations, Essays (1625)

All innovations involve risk and there is inevitable resistance to change. Why should we seek to innovate in anesthesiology education? Clinicians may ask, "It was good enough for me, why isn't it good enough for the current generation of residents?" There is certainly change in all aspects of life, and innumerable factors outside educational theory impact what, how, and why anesthesiology educators do what they do (Table 1). These contextual issues include an increasing international focus on patient safety and risk management initiatives. ${ }^{3}$ Highprofile cases of medical mismanagement have resulted in increased demands for accountability to the public., ${ }^{4,5}$ Research regarding anesthesia trainees who were taught in a traditional apprenticeship paradigm has identified poor unsupervised practice. ${ }^{6}$ Another interesting and important finding is an increased incidence of anesthesia-related morbidity and mortality occurring at the beginning of the academic year. ${ }^{7-9}$ In addition, there is a considerable body of evidence documenting the negative effects of sleep deprivation in both trainees and staff, and many jurisdictions have mandated reduced working hours, which, in turn, has resulted in concerns of decreased training opportunities and lack of continuity of medical care..$^{10,11}$ One of the largest changes in medical education over the past 25 years has occurred in the United States as a result of the impact of managed care. There has been an actual decrease in the opportunity to learn from each patient's set

Table 1 Evolving contextual issues affecting anesthesiology education

1. Reduced opportunities for patient contact due to an increased emphasis on efficiency and cost containment in healthcare (managed care in the United States and its counterparts in Canada and elsewhere) and work hour reforms;

2. The necessity to rethink educational practices that may increase risk to patients due to the patient safety movement and an increasing demand for accountability to patients;

3. Increasing difficulty to master any part of the medical literature due to an exponential growth in medical knowledge and technology; and

4. Increasing understanding of the importance of the non-medical expert CanMEDS roles which have traditionally been neglected in both formal teaching and assessment of circumstances due to the shift of patient care from the hospital environment to a more outpatient-based model. ${ }^{12}$ These cultural and societal changes demand a reconsideration of medical education. Other relevant issues include increasing medical commercialism, the continuing exponential increase in medical knowledge and medical technology, the often complex evaluation and accreditation of foreign medical graduates, and society's varying perceptions and expectations of anesthesiologists as professionals.

The $21^{\text {st }}$ century anesthesiology educator is faced with some challenging questions. As a specialty, how can we ensure that residents are trained adequately to deal with the ever increasing complexity of the modern healthcare system while simultaneously structuring training programs to minimize the fatigue shown to lead to medical error and burn out? Is it possible to improve the efficiency of training programs so that residents learn more in a shorter period of time? Is it possible to reduce the risks to patients inherent in anesthesiology training, especially in the earlier phases of learning? How can we assess the cost-effectiveness and efficacy of new technologies for use in medical education? What is the most effective means to teach residents the knowledge base and skill sets for rare events so they can retain the acquired skills for when they are needed? It is questions such as these that point us in a direction well beyond traditional medical literature. Fortunately, researchers in other fields are beginning to study medical education with different perspectives that can help to answer some of the questions posed above. In the following two sections of this article, we discuss the value of reviewing the literature from a broad range of disciplines and the importance of using a correspondingly broad variety of research methods that are often a significant departure from quantitative biomedical research methods.

\section{The influence of other disciplines on medical education}

As medical educators, we argue that we must look outside our own field for innovation. It is useful to consider the related knowledge base in a diverse range of other fields, including psychology, sociology, anthropology, bioethics, kinesiology, and human factors research. ${ }^{13}$ The recent crosscutting edge series of articles published in the journal, Medical Education, celebrates this multidisciplinary nature by presenting "cutting edge research from another discipline of study that cuts into the field of medical education". ${ }^{14}$ One example from this series that has particular relevance to education in anesthesia is the article by Martimianakis $\mathrm{et} \mathrm{al}$. which considers some of the sociological interpretations of professionalism ${ }^{15}$ (along with two accompanying commentaries). ${ }^{16,17}$ Although Martimianakis et al. acknowledge 
the need to identify unacceptable and unprofessional behaviour, they raise the concern about a "checklist conception" of professionalism characterized by defining criteria of competence and behavioural assessment. It is argued that defining professionalism in this manner is inadequate, and broader economic, political, and social dimensions must be incorporated into our understanding. Martimianakis et al. also review the concept of interprofessionalism; if professionalism is not merely an individual's traits and behaviours but relates to complex interactions amongst different professional groups, patients, and institutional structures, how can we expect to teach or to assess professionalism adequately in professional silos? Reflected in this point is the increasing focus on interprofessional education in the medical education literature. Martimianakis et al. also consider social constructivist ideas of professionalism as "boundary work" that enables professional groups to protect markets, e.g., the creation of a boundary between obstetrics and midwifery from 1900 to 1930 in the United States. ${ }^{18}$ It could be argued that these issues are pertinent to the current relationships between nurse anesthetists and anesthesiologists in the United States. Cross-cultural differences, e.g., the different roles played by anesthesiologists, nurse anesthetists, anesthesia assistants, and operating department practitioners in Canada, the United States, and the United Kingdom, speak to the idea that any definition of the "profession" of anesthesiology is socially constructed. More contrasting comparisons can be made regarding the status of anesthesiology in the global South where, in many jurisdictions, anesthesia is delivered almost exclusively by non-physicians. It is the view of many that establishing cadres of well-trained non-physician anesthetists is essential to reducing mortality in practice settings where resources are limited, but this view may not always be accepted by local physician anesthesiologists. ${ }^{19}$ It can be argued that strengthening a physician-based anesthesiology profession is essential for effective advocacy amongst other more established medical specialties.

Cognitive and experimental psychology can provide medical educators with insight into factors of potential clinical importance, such as attention; ${ }^{20}$ perception and pattern recognition; ${ }^{21-24}$ the encoding, retrieval, and retention of memory; ${ }^{25-28}$ clinical reasoning and decision making; $;^{20,29-31}$ the nature of expertise $;^{20,32-34}$ feedback; $;^{35}$ individual differences in learning; $;{ }^{36}$ self-assessment; ${ }^{37}$ and the effects of stress and fatigue. ${ }^{38}$ An area of emerging interest in cognitive psychology is the observation that information retained through repeated testing surpasses that of repeated studying, especially if testing is spaced over time. ${ }^{39}$ This phenomenon builds on our understanding of the educational concept of formative assessment (assessment to promote learning) ${ }^{40}$ and has been shown to be clinically relevant in teaching in-hospital resuscitation skills. ${ }^{41}$ The testing effect has the potential to improve educational outcomes and, therefore, improved management of critical events that are infrequent but require immediate assessment and therapeutic intervention. Examples of important research studies from disciplines outside of medicine that nevertheless have relevance to education in anesthesia are too numerous to be dealt with comprehensively in an overview such as this paper. Herein, we highlight selected important recent research, and other examples are presented in Table 2. Additionally, this theme issue includes a further article in which the influence of psychology and human factors on anesthesiology education is explored. ${ }^{42}$

As an important means to foster answers to pressing research questions in anesthesiology education, other disciplines should use a broader range of research methodologies (discussed in the following section) than is found in traditional clinical research.

\section{Medical education: research principles and methodology}

As clinicians, it is natural to compare educational research methods to more familiar methods used in clinical research. However, medical education is a very different field to clinical medicine. Perhaps it is best at first to step back and consider the big picture, i.e., what constitutes the nature and limitations of knowledge (epistemology)? For instance, it is often stated that the randomized controlled trial is the optimal design for reducing threats to validity in clinical research, but is this study design optimal, applicable, or even desirable for medical education research? Furthermore, it is difficult to know which, if any, standardized reporting guideline (e.g., the Consolidated Standards of Reporting Trials [CONSORT] at http://www. consort-statement.org) might apply to medical education research.

The randomized controlled trial is considered to be the gold standard in assessing healthcare interventions. ${ }^{43}$ This methodology has also been applied successfully to educational research, a notable example being Ahlberg et al.'s observation that randomizing residents-in-training to virtual reality simulation training reduces both errors and surgical times for laparoscopic cholecystectomy. ${ }^{44}$ Such quantitative methods lend themselves well to the evaluation of teaching discrete psychomotor skill sets for which it is relatively straightforward to define objective goals and endpoints and for which subjects have little relevant prior experience. It is challenging to consider how the same methodology could be used to evaluate an intervention 
Table 2 Studies from disciplines outside medicine that impact anesthesiology education

\section{Beyond monitoring: distributed situation awareness in anesthesia ${ }^{129}$}

Part of a British Journal of Anaesthesia theme issue on human factors, this review provides insight from human factors research into the key nontechnical skill of distributed situation awareness and its failure, resulting in fixation error. The authors define situation awareness not simply to collect and process information but "to direct a course of personal interactions with the environment towards a goal...(a) bidirectional process of searching for information to act and acting to acquire information." Historically, non-technical skills have not been part of the formal anesthesiology curriculum. The authors discuss how teaching and evaluating situation awareness remains a challenge that can clearly impact patient safety.

\section{Self-assessment in the health professions: a reformulation and research agenda ${ }^{37}$}

Self-assessment is widely considered key to directing lifelong learning and to maintaining competence. Eva and Regehr cite literature from psychological fields of personality theory, metacognitive theory (knowledge of one's own knowledge), social psychology, and models of the development of expertise to challenge the narrow conception of self-assessment dominating the education literature as retrospective and summative. They discuss the little studied state of reflection-in-action, which allows clinicians to step up cognitive resources during a situation and allows decision-making regarding whether they are competent to achieve their goals or need to seek help. They challenge the presumption that individuals are "good" or "bad" self-assessors and emphasize the importance of context. They discuss how overestimating self-efficacy can have advantages that partially balance the obvious disadvantages of overestimating one's abilities.

\section{A culture of safety or coping? Ritualistic behaviours in the operating theatre ${ }^{130}$}

This anthropological perspective on intraoperative risk management notes how ritualistic behaviours normalize risk in the operating room environment, including the toleration of risk that contrasts with the public discourse on critical incident reporting. They suggest that trainee anesthesiologists must experience risk to be able to ultimately "recognize the boundaries between insignificant and significant danger, and accordingly... to accommodate these situations within the parameters of their acquired expertise."

\section{Affect is central to patient safety: the horror stories of young anesthetists ${ }^{131}$}

Part of a special patient safety themed issue of Social Science and Medicine, Iedema et al. performed a text analysis of transcripts from discussions of trainee anesthesiologists nominated to the Australian and New Zealand College of Anaesthetists for having leadership potential. They analyze aspects of the hidden curriculum related to horror experienced in training. A trainee says "....anaesthetists are quite stressed people a lot of the time, I suppose, and quite obsessive. And the pendulum of confidence where you start thinking it's really difficult swings the other way and it's really quite easy, and then you have your first horrible disaster and it's all really difficult again, and you keep swinging through your career, but the oscillations get smaller, just so it's okay..." They discuss the educational impact of horror, including the use of personal distress and moral uncertainty as teaching devices, the value of informal narratives relating to critical incidents, and how affect influences the ability to learn from adverse outcomes

\section{Motor skill learning and performance: a review of influential factors ${ }^{132}$}

This review of the kinesiology and psychology literature identifies factors that improve the learning of motor skills. "Observational practice" has been discounted as inferior to physical practice; however, recent research has demonstrated that alternating observation and physical practice results in better retention of motor skills compared with physical practice alone. Feedback with an internal focus, e.g., the movement of a hand, has been shown to be less effective than that with an external focus, e.g., the movement of a tool or instrument in that hand. Feedback on the best performances results in better retention of skills than if feedback is given on the worst performances, i.e., the conviction of being good at a motor task improves learning. "Self-controlled practice" where feedback is requested from the learner results in improved motor skill learning compared with predetermined feedback schedules.

intended to teach domains, such as professionalism or health advocacy, for which there is likely to be significant variation in baseline behaviour and no well-established measurement tools. ${ }^{45}$

Clearly, some research questions in education require solutions that cannot be addressed by the more familiar quantitative methodologies. Qualitative methods employ a wide range of tools, including focus groups, ${ }^{46}$ research interviews, ${ }^{47}$ participant observation, ${ }^{48}$ and textual analysis. However, qualitative methodologies are probably better described by their similarly diverse range of underlying theoretical approaches, such as ethnography, ${ }^{48,49}$ phenomenology, and grounded theory (Table 3). ${ }^{50}$ In addition, researchers using qualitative methodologies often apply epistemological viewpoints that are very different from the dominant (positivist) paradigm of science and medicine, which states that knowledge is based on experimentation and measurable evidence. ${ }^{51,52}$ Qualitative researchers may approach a research question with the perspective that it is not possible to be independent and subjective as a researcher; that the researcher should acknowledge her/his own involvement in the analysis and interpretation of data (reflexivity); that there are no absolute or generalizable truths; or that the role of research includes challenging existing power relations and hierarchies. ${ }^{52}$ For instance, a key stance of the qualitative approach is the assumption of the uniqueness of every individual's experience and every event, whether measured or not. The variety of different methodologies and theoretical backgrounds can make it difficult for those with a quantitative background to appraise qualitative research; other reviews provide guidance on this matter. ${ }^{53-55}$

It is easy then to see why qualitative research can be challenging, and this difference has often produced a 
Table 3 Some recent research questions in anesthesiology education investigated with qualitative methods

\section{Professional Artist, Good Samaritan, Servant, and Co-ordinator: four ways of understanding the anaesthetist's work ${ }^{133}$}

Larssen et al. asked how anesthesiologists understand their work, in order to develop an understanding of clinical competence that goes beyond theoretical knowledge and practical skills. They used a phenomenological approach, which assumes that phenomena are understood by different people in qualitatively different ways, and they collected data using interviews. They found different ways of understanding the same "thing" - the anesthesiologists' work - including the "Professional Artist" who manipulates physiological processes with practical work and the "Good Samaritan" who guides the patient safely and comfortably through surgery.

Investigation of trainee and specialist reactions to the mini-Clinical Evaluation Exercise in anesthesia: implications for implementation $^{134}$

Weller et al. asked what the effects were of implementing a new form of workplace-based evaluation. They used a grounded theory approach in contrast to the scientific method, i.e., rather than beginning with a hypothesis that is tested, data is collected first and then attempts are made to generate theory from the data through an interactive process of coding and re-coding. They used interviews and focus groups to collect data. Although many subjects found the mini-CEX improved feedback, they found cultural issues (e.g., unwillingness of assessors to deal with unsatisfactory performance) and unintended consequences (e.g., deterioration in some trainees' performance) with in-training assessments.

Expertise in practice: an ethnographic study exploring acquisition and use of knowledge in anaesthesia ${ }^{95}$

Smith et al. aimed to describe and define expertise in anesthesiology practice. They used an ethnographic approach, which typically involves a prolonged period of observation of an environment and aims to describe the nature of what is studied and to find meaning in it. They used participant observation and interviews to collect data. They discuss the role of tacit knowledge (i.e., knowledge that has not been or cannot be explicitly stated) in expertise.

qualitative-quantitative divide. ${ }^{56,57}$ However, it is becoming increasingly apparent that any question as to the absolute validity of quantitative or qualitative methodology is irrelevant. Both methodologies are appropriate for different goals, and one must first decide the nature of the research question before deciding the most appropriate methodology. ${ }^{58}$ Moreover, the combination of both quantitative and qualitative methodologies is now increasingly seen in one study (mixed methods research), ${ }^{59}$ though further developments are required to take full advantage of this approach.

Recent editorials in this ${ }^{60}$ and other anesthesia journals have highlighted qualitative methods. ${ }^{61}$ In 2009 , a fine example of qualitative research in anesthesia education was highlighted in the journal Anesthesiology as one of the most important publications of that year. ${ }^{62}$ In their study, Waisel et $a l .{ }^{63}$ investigated challenges faced by anesthesiology residents in obtaining informed consent by performing textual analysis using the principles of grounded theory whereby themes are allowed to develop through an iterative process of coding data. Anesthesiology residents faced complex challenges, including patients' mistrust towards healthcare professionals in general, questioning of trainees' competence, and misunderstandings in the consent process that were not fully resolved. It should not be difficult to imagine how related issues could be explored further with this approach. Such examples could include cultural issues and contextual factors that determine the degree of trust that patients place in healthcare professionals as well as issues of accessibility to healthcare in various jurisdictions. In Table 3, there are detailed examples of recent research questions in anesthesia education that have been explored using various qualitative methods and epistemological assumptions.
In several recent articles, Cook et al. adopted a somewhat different approach by classifying educational research according to the purpose of the research rather than according to methodology. ${ }^{64,65}$ Descriptive research is used to disseminate educational innovations. Justification research aims to compare new educational interventions with existing practice and is more akin to clinical research. Clarification research aims to identify how and when to best use educational interventions. Rather than asking "Does simulation-based education work?" clarification research might ask "How should residents be debriefed following their simulation session to best identify their personal performance deficits?" Currently, findings in most medical education literature are reported as either descriptive research or justification research; there have been calls for more clarification research that is well grounded in educational theory.

\section{Educational curricula}

After considering the drivers to change and looking outwards to other relevant fields and research methods, it is essential to consider how this theoretical background affects our performance as teachers and educators. Before discussing teaching, learning, and assessment in anesthesiology, we will consider the application of theory to practice in curricula. Although curriculum is often considered to be the "content" of an educational program, ${ }^{66-69}$ its broader definition includes the teaching and learning strategies related to that content, the assessment of learners, and evaluation of the program. ${ }^{70}$ Hence, curricula can be seen as the overall educational plans. A still broader definition includes: a) the informal curriculum, which 
describes that which is not planned or taught but is nevertheless learned during interpersonal interactions with patients, other learners, and healthcare professionals during anesthesiology training, and b) the hidden curriculum, which refers to wider structural and cultural issues that result in the socialization of medical trainees (Fig. 1). ${ }^{71,72}$ Table 4 shows key issues in anesthesiology curricula that are discussed further in this section.

Various organizational issues result in considerable international variation in the postgraduate anesthesiology curriculum, e.g., length of training, comparative emphasis on training or service, amount of time spent in the core specialty, and the amount of time "off-service" in other specialties. Historically, there has been considerable debate as to whether critical care medicine is considered a core specialty in itself or an extension of other specialties, such as anesthesiology or respiratory medicine. There is also considerable variation in terms of the timing of certifying examinations related to completion of training as well as the methods of in-training assessment. These variations have as much to do with historical and political factors as they have to do with educational theory. ${ }^{73}$ Traditionally, the specialties of anesthesiology and critical care medicine have been seen as postgraduate specialties; however, the appreciation that certain skills, such as basic airway

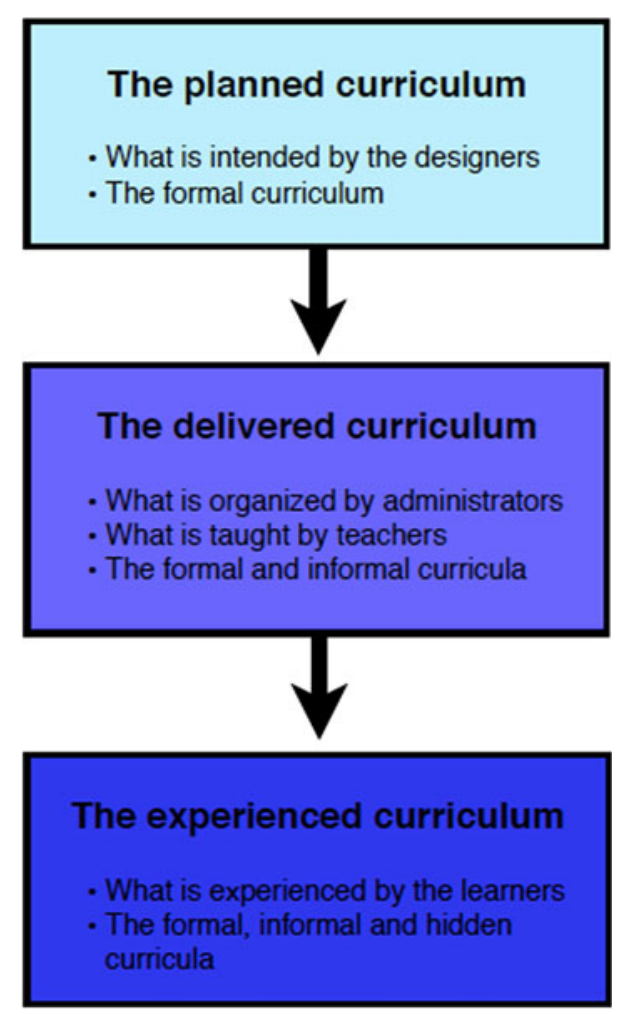

Fig. 1 The three levels of a curriculum, as described by Prideaux ${ }^{135}$
Table 4 Key issues in anesthesiology curricula

1. The integration of simulation and new learning technologies into existing curricula;

2. The challenge to fulfill the promise of inter-professional education; and

3. A shift in focus from a time-based apprenticeship model to competency-based education.

management and the recognition of the critically ill patient, should be learned early in one's clinical training has seen anesthesiology increasingly integrated into undergraduate curricula. Wong recently provided an in-depth review of theoretical principles of curriculum development in anesthesiology with particular reference to the undergraduate curriculum at McMaster University. ${ }^{74}$

Curricula are necessarily in a constant state of change prompted by the drivers discussed above, including a continuously evolving knowledge base, changing societal needs, and feedback from program evaluation. In addition, current trends in medical education present a number of challenges to anesthesiology curricula. There is constant evolution of simulation technology, ${ }^{75}$ which is increasingly recognized as offering a unique learning opportunity ${ }^{76}$ without exposing patients to risk. ${ }^{77}$ It is an ongoing challenge to determine how simulation and other educational technologies, such as $e$-learning, ${ }^{78}$ can best be integrated into existing anesthesiology curricula. Much of professional practice in anesthesiology relates to interactions with other specialties and healthcare professionals. Interprofessional education is currently a key theme in the medical education literature, ${ }^{79}$ and although the evidence base is still weak in this area, it was suggested in a recent Cochrane review that interprofessional education can improve healthcare processes and outcomes. ${ }^{80}$ Interprofessional education seems especially suited to the learning of CanMEDS roles such as communicator and collaborator; ${ }^{2}$ however, postgraduate education remains predominantly in professional silos. Interprofessional education presents the logistic and organizational/cultural issues involved in gathering different professional groups with the ultimate goal of improving quality of care through coordinated curriculum design - one can easily imagine the potential contributions of social psychology or sociology to this problem, as noted above. A related issue is the challenge of assessing a team's performance in certain skills, e.g., cardiopulmonary resuscitation, for which teamwork is critical to patient safety but for which current assessments are preoccupied with individual performance. ${ }^{81}$ This is an especially vexing challenge given that the unit of professional certification will remain at the level of the individual for the foreseeable future. Creative solutions in this area are sorely needed to enhance the quality of teamwork, and 
we will likely need to look outside the disciplines of medicine and medical education, e.g., drawing lessons from the aviation industry. Certainly, a culture of continuous assessment would be beneficial at both the individual and team levels.

Postgraduate anesthesia training has long been based on the Halstedian apprenticeship model. ${ }^{82}$ Currently, competency-based education is the most influential idea in medical education curricula, i.e., to consider standardized measurable competencies as the central issue on which to base the entire curriculum. Outcome-based curricula have been described as defining a curriculum backwards, i.e., instead of emphasizing the instructional process of the curriculum, the desired competencies determine the content, teaching, and assessment. Competencies have become the "unit" of education ${ }^{83}$ in many jurisdictions found within competency frameworks, such as the Outcome Project of the Accreditation Council for Graduate Medical Education (ACGME) in the United States ${ }^{84,85}$ and CanMEDS in Canada and some other countries. ${ }^{2}$ Recently, Frank et al. reviewed the theoretical basis of competencybased medical education as part of a theme issue in the journal, Medical Teacher. ${ }^{83}$ Advocates of competencybased education argue that a focus on competency in specified domains will allow greater public accountability and greater responsiveness to societal needs. Competencybased education moves away from a preoccupation with knowledge and places more emphasis on skills and attitudes. It is argued that a curriculum of competencies can engage and empower learners by providing a transparent path to well-defined outcomes. ${ }^{83}$ In competency-based education, it is possible to tailor the duration of training to individual learning rather than expecting competence to diffuse over a pre-specified amount of time as in the "teabag model". ${ }^{86}$ However, competency-based medical education is not without controversy, including ideological differences in opinion and epistemology and doubts that quantitative research methods can answer these "bigger" research questions adequately. Those who argue against competency-based education have the view that reducing medicine to a series of core competencies neglects bigger, important (but less observable) issues, such as medical altruism, the integration of knowledge into a cohesive whole, striving for excellence rather than for a minimum standard, and working as part of a team. ${ }^{87}$ The results of a recent review of the literature indicated that it may be exceedingly difficult to assess performance in certain domains of the ACGME competency framework, such as "systems-based practice" and "practice-based learning and improvement". ${ }^{88}$ The challenges of introducing a competency-based curriculum have resulted in hybrid systems where elements of competency-based medical education have been combined with traditional apprenticeship curricula. There is much research to be done regarding issues such as the unintended consequences of introducing frequent formal competency assessments into training and into the interactions between competency-based education and the culture of medicine.

\section{Teaching and learning in anesthesiology}

For the majority of anesthesiologists in academic health centres, the significance of medical education theory will probably be best described by how well it translates into the practice of formal and informal teaching of residents. Teaching and learning in anesthesiology may be achieved through a variety of means, including small-group ${ }^{89,90}$ or large-group ${ }^{91,92}$ didactic methods, each with its advantages and disadvantages. ${ }^{74}$ However, experiential learning is necessary to integrate the "book" knowledge into a practical skill set in anesthesiology ${ }^{93}$ as well as to learn tacit knowledge that is not (or cannot be) made explicit. ${ }^{94,95}$ The focus of this section on teaching and learning in anesthesiology is on two types of experiential learning-clinical teaching and simulation-which dominate the literature in anesthesiology education research.

\section{Clinical teaching}

Despite the mainstream acceptance of simulation-based education, the majority of teaching and learning in anesthesiology and perioperative care is, and is likely to remain, in clinical settings, such as the operating room, the critical care unit, or the emergency department. Anesthesiology has its own particular challenges and opportunities for the "clinician teacher". The operating room can be an uncomfortable or threatening experience for a novice. Masks can hinder non-verbal communication. ${ }^{93}$ Patient safety and comfort must be balanced against a responsibility to the learner. ${ }^{96}$ The patient is present throughout the case, and although periods of uneventful maintenance of anesthesia may allow in-depth case-based discussions, the primary responsibility must always be to the unconscious patient. More challenging cases may only allow the clinical teacher to demonstrate clinical management with the learner taking a more passive role. Teachers may also have to choose between providing a teaching opportunity and maintaining the efficiency of an operating list, ${ }^{96}$ and learners may be inhibited if they perceive their teachers (or other operating room staff) to be impatient. Trainees often work with a large number of different clinical teachers, and they can find the variety in practice confusing. ${ }^{97}$ An operating list of many short cases with rapid turnover makes it difficult to develop any discussion; ${ }^{98}$ anesthesiologists must then be skilled at identifying and using the 
"teachable moment". How can the medical education literature inform how we improve clinical teaching in anesthesiology?

Sutkin et al. recently reported a systematic review asking the question, "What makes a good clinical teacher in medicine?" The most commonly reported themes included the importance of being a content expert and possessing non-cognitive attributes, such as creating a positive learning environment, having excellent listening skills, enthusiasm for medicine, enthusiasm for teaching, and enthusiasm in general. ${ }^{99}$ Cleave-Hogg interviewed anesthesiologists who had been identified a priori as excellent clinical teachers and asked them what led to their success. They reported similar themes, including willingness to give one's own time for teaching, enjoyment of one's own profession, continually enriching one's own learning, and an ability to establish and maintain interactive professional relationships. $^{98}$

Many clinicians in teaching hospitals have received no formal training in how to teach ${ }^{81}$ and base their teaching methodology on intuition and their own learning experiences. ${ }^{1}$ Although, as described by Sutkin and Cleave-Hogg, many of the attributes of a good clinical teacher relate to personality, clinicians can certainly be taught how to improve their teaching. The value of faculty development to encourage even simple measures, such as establishing learning objectives and discussing these with trainees, cannot be over-emphasized. ${ }^{100,101}$ Further refinement would include conducting a needs assessment or gap analysis, and developing a plan for evaluation. ${ }^{102}$ Techniques that can improve clinical teaching in the operating room are detailed in Table 5. Good clinical teachers are characterized by an "inquiry" approach to teaching, i.e., getting residents to think through complex situations using Socratic questioning. ${ }^{98}$

Feedback, described as the "cornerstone of effective clinical teaching", ${ }^{103}$ has been found to be particularly challenging for clinical teachers ${ }^{98}$ and has been the subject of recent reviews. ${ }^{103,104}$ Having a culture of feedback is important and should be viewed as a normal component of the teacher-learner relationship. In contrast to the simulation debriefing literature, there is a paucity of research on clinical teaching and feedback in the operating room. Some guidance for effective feedback in clinical teaching is summarized in Table 5.

Other factors that have been identified as promoting excellence in clinical teaching include using senior educators as mentors for junior faculty and rewarding excellence in teaching as equivalent to excellence in research. ${ }^{99,100}$ The opportunity to have teaching evaluated by peers or experts allows valuable feedback; however, this is often not feasible with the practical constraints of clinical teaching. ${ }^{100}$ Evaluation of anesthesiologists' teaching
Table 5 Techniques to improve clinical teaching in the operating room

Before the case

- Identify the learner's basic level of knowledge ${ }^{98}$

- Identify learning goals ${ }^{100}$

During the case

- Help the learner to develop an anesthetic action/organization plan for each patient ${ }^{98}$

- Use an open-ended questioning approach to challenge understanding ${ }^{98}$

- Challenge the learner to be prepared for the unexpected ${ }^{98}$

- Provide supervision appropriate to the case ${ }^{98}$

After the case

- Find time for feedback ${ }^{98,104}$

- Feedback should focus on the task, not the individual ${ }^{103,104}$

- Feedback should focus on one or two items to prevent overwhelming the learner ${ }^{103}$

- Feedback should not undermine self-esteem but should not simply consist of praise $\mathrm{e}^{103,104}$

- Feedback can be delayed, but the information that informs the feedback should not be recorded retrospectively. ${ }^{104}$ Feedback is most effective if given at the time of an event or shortly afterwards $^{103}$

- Motivated recipients benefit from feedback that facilitates the learner's own reflections ${ }^{104}$

- Feedback should include a discussion of what the learner can practically do to improve future performance ${ }^{103}$

with feedback from residents has been shown to improve teaching. ${ }^{105}$

Simulation-based education

Simulation is a term that covers an increasingly broad range of techniques and technologies ${ }^{75,106-110}$ that share the characteristics of providing the opportunity for experiential learning without exposing patients to risk. ${ }^{77}$ Anesthesia was an early leader in simulation for medical education, and the adaptation of Crisis Resource Management from aviation's Crew Resource Management is well described. There has been a tendency in aviation and other high-stakes high-reliability industries to introduce simulation without researching its advantage compared with other educational methods. David Gaba's statement that "no industry in which human lives depend on the skilled performance of responsible operators has waited for unequivocal proof of the benefits of simulation before embracing it" is often quoted $^{111}$; however, this sentiment contrasts with the prevailing emphasis for an evidence-base in clinical medicine. Simulation has become a mainstream enterprise in medical education, and the need to identify the most effective and most cost-effective aspects of simulation has resulted in simulation research dominating the recent literature in anesthesiology education. Perhaps the research that most 
convinces sceptics of the value of simulation are those "justification" studies ${ }^{65}$ that show the translation of skills taught in the simulator to clinical practice. Hall et al. reported a study which evaluated paramedics learning tracheal intubation using either a high-fidelity simulator or routine training on anesthetized patients. Later, both groups were evaluated on anesthetized patients, and the simulator group performed with competency similar to that of the control group despite not having previously performed tracheal intubation. ${ }^{112}$ Similarly, Barsuk et al. identified a reduction in complications and costs from catheter-related septicemia after simulation-based learning, ${ }^{113}$ and Wayne et al. found that trainees who had undergone simulatorbased learning adhered more closely to the American Heart Association guidelines during cardiac arrest. ${ }^{114}$ Finally, Bruppacher et al. showed that residents who were randomized to simulation-based learning performed better than a control group of residents who had a case-based tutorial related to the complex task of weaning a patient from cardiopulmonary bypass. Performance in cognitive and interpersonal non-technical skills was also superior in the simulation group. ${ }^{115}$

Issenberg's group has performed a series of reviews on simulation-based education. ${ }^{76,116}$ They identified feedback as the most important feature that promotes learning in simulation, but they noted a need for more research on how best to deliver feedback. They also commented that simulation offers the advantage of deliberate practice that is a key part of the development of expertise ${ }^{32,33}$ and the related concept of mastery-learning where skills are practised until a minimum mastery standard is achieved before moving on to the next educational unit.

\section{Assessment in medical education}

In his review of assessment in medical education, Epstein reported the common scenario of an attending physician receiving a form requesting an evaluation of a trainee's competencies in diverse areas (e.g., procedural skills, professionalism, and system-based practice), and he noted the reaction of the attending physician questioning whether brief interactions with that trainee were sufficient to provide a meaningful assessment. ${ }^{117}$ Epstein also noted that we might question the validity of all other types of assessment that occur during training, such as multiple choice questions (MCQ), Objective Structured Clinical Examinations (OSCEs), short-answer questions, and oral examinations. Instead, we suggest that we as clinicians often assume that board examinations will cover any deficiencies in workplace-based assessment, and we give little further thought about the way in which these different forms of assessment work together to form a system of evaluation.
The first question to consider is "What is the purpose of our assessment?" Assessment can be either formative or summative. Formative assessment is designed to promote further learning; it identifies deficiencies in knowledge, skills, or attitude and motivates further learning. Tools for formative assessment should therefore be designed to provide rich and timely feedback. Summative assessment aims to judge competence, readiness for a lower level of supervision, or fitness for independent practice. Ideally, both types of assessment should have robust psychometric properties: they should be reliable (i.e., similar results would be produced if a different assessor administered the test) and valid (i.e., the test is really testing the skill/s we want it to test).

Taxonomies of assessment, such as Miller's pyramid, are useful for identifying different levels of performance that may be assessed with different tools (Fig. 2). ${ }^{118}$ Written tests, such as MCQs and oral examinations, can assess the "knows" level of factual information. When designed to be rich in clinical context, the same tools probe the integration of that knowledge into clinical judgment and decision-making, i.e., the "knows how" level of assessment. ${ }^{117}$ It has been suggested that simulation has advantages over the oral examination in the domain of crisis management because it can assess the actions trainees would actually perform (the "shows how" level of performance) rather than what they say. ${ }^{119}$ Consequently, simulation has been introduced in various forms into the anesthesia board examinations in Israel, the United Kingdom, and more recently, Canada, ${ }^{120}$ although the use of simulation for high-stakes assessment remains controversial. The "does" level of assessment can be performed only in the workplace by the expert anesthesiologists who are supervising trainees. All of these levels of assessment should be incorporated into a comprehensive system of assessment, and even the most robust board examinations

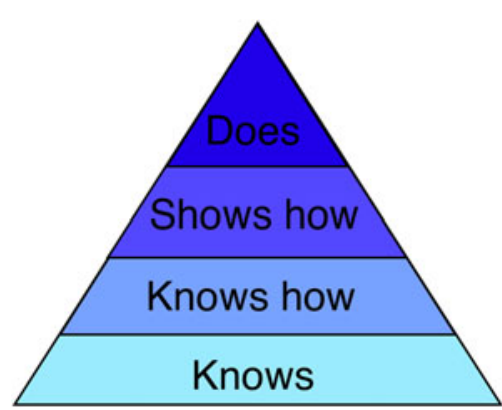

Fig. 2 Miller's pyramid. This diagram illustrates hierarchical levels of performance that can be used to assess learning. The bottom two levels refer to cognition: "Knows" refers to the retention of factual information, and "knows how" refers to the interpretation and integration of this knowledge into a management plan. The top two levels describe behaviour: "Shows" refers to a demonstration of learning, and "does" refers to an assessment of actual clinical practice 
cannot compensate for a failure to assess actual practice in the workplace.

Therefore, what competencies should be assessed? There has been a recent international move towards the use of explicit frameworks of competencies. The CanMEDS model places the medical expert role at the core of six overlapping roles or domains of competency: scholar, manager, communicator, collaborator, health advocate, and professional. The corresponding model in the United States is the Accreditation Council for Graduate Medical Education (ACGME) which has six domains of competence: medical knowledge, patient care, professionalism, communication and interpersonal skills, practice-based learning and improvement, and systems-based practice. ${ }^{85}$

A wide variety of different assessment tools are necessary to assess such different domains of performance, and a detailed review of individual tools is outside the scope of this review. A retrospective global rating after a lengthy period of unstructured observation has inappropriate qualities for summative evaluation. van der Vleuten writes, "Research indicates that the human mind is easily led by what we think we have seen, usually based on gross generalizations of a few cues or samples of performance which do not necessarily coincide with reality." 121 Psychometric properties are unsurprisingly stronger for psychomotor skills ${ }^{122}$ than for more subtle cognitive and interpersonal skills assessment. ${ }^{123}$ Training improves the inter-rater reliability of assessments, speaking to the value of education-focused faculty development. Some areas of competency, such as professionalism, provide the same challenges discussed previously regarding quantitative research; no psychometrically robust tools have been developed to assess a construct over which there is considerable disagreement regarding its definition. ${ }^{15,45}$ Few would argue the central importance of professionalism to anesthesia practice. In that case, where does this leave the clinical educator reliant on traditional assessment tools? Qualitative methods of evaluation may be more fruitful than attempting to map this construct onto a numerical scale. Perhaps we should also consider alternative frameworks for judging assessment tools, including those recommended for evaluating qualitative research ${ }^{55,124}$ : Is the method of sampling appropriate? Did the assessor acknowledge his or her own influence in the assessment of behaviour? Is the information triangulated with other sources of information? What is the credibility of the information? Posing such questions might assist us in developing alternative approaches to assess problematic areas, such as teamwork, ${ }^{117}$ as the question remains concerning the extent to which teamwork can be assessed as an individual competency.

van der Vleuten has noted that the literature on assessment in medical education is dominated by discussions regarding the psychometric properties of individual tools, without consideration as to how they fit into a larger system of assessment. ${ }^{125}$ In his literature review, he notes that reliability of assessment tools is not intrinsic to that tool, but sampling is far more important; most tools become reliable if used for at least four hours. He notes that subjective assessments, such as the mini-Clinical Evaluation Exercise (mini-CEX), can be as reliable as more objective tools.

Any assessment can have unintended consequences. Summative assessments influence learning even in the absence of feedback, as students "study to the test". Students may "cram" for examinations, reducing the chance of long-term retention of information, and they may substitute superficial knowledge for reflective learning if this is the content of the test. ${ }^{117}$ Other research has shown the following results: deterioration in the actual competency of students who were memorizing objective structured clinical examination (OSCE) checklists; an unexpected increase in rote memorization after a switch from MCQs to free response questions; and role conflict when facilitators in small-group teaching were requested to provide summative evaluations. $^{121}$

So what of the practical dilemma of the clinician asked to assess a trainee after only a few operating lists or interactions in the intensive care unit? Workplace-based training may be formative, and certain principles of providing good feedback apply, including finding time and a space free from distractions, encouraging the trainee to reflect on her/his personal performance, providing detailed feedback on a few key areas of performance, identifying areas of good practice, and identifying practical ways in which gaps in performance can be remedied in the future. Ideally, to make workplace-based assessment a useful part of summative evaluation, it should be performed prospectively for a pre-defined competency by an assessor who has been trained in the use of the assessment tool. Limitations should be acknowledged; every assessment tool has its strengths, weaknesses, and contextual issues. ${ }^{117,125}$ Certain tools are better for assessing different competencies, ${ }^{126}$ and multiple assessments over time can compensate for the failings of individual assessment tools from a single

Table 6 Key issues in anesthesiology assessment

1. All levels of Miller's pyramid (Fig. 2) should be included in a comprehensive system of assessment;

2. Immersive manikin-based simulation holds the promise of objective assessment of the "shows how" level of performance, but its use for high-stakes summative assessment remains controversial;

3. Anesthesiologists work at the level of a team but are assessed at the level of individuals; and

4. There are often unintended consequences to assessment, such as affecting what is studied as students "study to the test". 
clinical encounter. ${ }^{127}$ Key issues in anesthesiology assessment are outlined in Table 6 .

Other important issues in assessment include post-certification lifelong learning. How valid is the assumption that our self-assessment is an appropriate method for directing continuing professional development? How can we ensure that our profession's contract with society is fulfilled by the career-long maintenance of competence? These and other related issues are explored further in articles appearing in this issue of the Journal.

\section{Conclusions}

In this review, we have attempted to provide a broad overview of current and emerging issues in anesthesiology education. Medical education is vital to anesthesiology. Along with research and clinical service, education represents one of the "three legs" of academic medicine. ${ }^{128}$ In many ways, however, medical education is separate from the other two legs due to its multidisciplinary nature. Academics in fields, such as psychology, sociology, medical anthropology, and kinesiology, are invested in medical education and make vital contributions to this branch of learning. We argue that embracing the diversity of these other relevant fields is a key aspect of truly innovative work in medical education. These fields often have challenging theoretical backgrounds and research methodologies that can inform curricula, teaching, and evaluation in anesthesiology. The use of research from other disciplines is probably underutilized in anesthesiology. Cross-referencing research from other disciplines and methodologies could be useful to investigate questions such as: How should we provide feedback on a task so the task is better performed the following week rather than better performed only immediately following the feedback? What are the implications of assessing resuscitation training as a team activity? How should we teach health advocacy in anesthesia? Can competency-based education cause medical education to respond more effectively to societal needs? Should simulation be used for high-stakes evaluation?

The purpose for this review is to promote further interest in a large body of peer-reviewed literature that is relevant to enhancing educational opportunities in anesthesiology and related disciplines. Hence, we aimed to highlight relevant questions rather than to answer them. Other articles in this issue will expand on this discussion and further explore some of the key issues in anesthesiology education.

Financial support Funded by the Department of Anesthesiology, University of Ottawa.

Conflicts of interest None declared.

\section{References}

1. Schwartz AJ. Resident/fellow evaluation of clinical teaching: an essential ingredient of effective teacher development and educational planning. Anesthesiology 2010; 113: 516-7.

2. The Royal College of Physicians and Surgeons of Canada. CanMEDS 2005 Framework. Available from URL: http://rcpsc. medical.org/canmeds/bestpractices/framework_e.pdf (accessed May 2011).

3. Kohn LT, Corrigan JM, Donaldson MS. To Err is Human: Building a Safer Health System. Washington, DC: Institute of Medicine, National Academy of Sciences; 1999.

4. Asch DA, Parker RM. The Libby Zion case: one step forward or two steps backward? N Engl J Med 1988; 318: 771-5.

5. Smith R. All changed, changed utterly. British medicine will be transformed by the Bristol case. BMJ 1998; 316: 1917-8.

6. Friedman Z, Siddiqui $N$, Katznelson $R$, Devito I, Davies $S$. Experience is not enough: repeated breaches in epidural anesthesia aseptic technique by novice operators despite improved skill. Anesthesiology 2008; 108: 914-20.

7. Haller G, Myles PS, Taffe PV, Perneger T, Wu CL. Rate of undesirable events at beginning of academic year: retrospective cohort study. BMJ 2009; 339: b3974.

8. Nash $R$. The "killing season": does inexperience cost lives? Lancet 2009; 374: 1313-4.

9. Jen M, Bottle A, Majeed A, Bell D, Aylin P. Early in-hospital mortality following trainee doctors' first day at work. PLoS One 2009; 4: e7103.

10. Fernandez E, Williams DG. Training and the European Working Time Directive: a 7 year review of paediatric anaesthetic trainee caseload data. Br J Anaesth 2009; 103: 566-9.

11. Sim DJ, Wrigley SR, Harris S. Effects of the European Working Time Directive on anaesthetic training in the United Kingdom. Anaesthesia 2004; 59: 781-4.

12. Ludmerer KM. Time to Heal. New York: Oxford University Press; 1999.

13. Eva KW. Covering up the crystal ball. Med Educ 2008; 42: 330-2.

14. Eva $K W$. The cross-cutting edge: striving for symbiosis between medical education research and related disciplines. Med Educ 2008; 42: 950-1.

15. Martimianakis MA, Maniate JM, Hodges BD. Sociological interpretations of professionalism. Med Educ 2009; 43: 829-37.

16. Morrison J, Dowie A, Cotton P, Goldie J. A medical education view on sociological perspectives on professionalism. Med Educ 2009; 43: 824-5.

17. Hafferty $F W$, Castellani B. A sociological framing of medicine's modern-day professionalism movement. Med Educ 2009; 43: 826-8.

18. Gieryn T. Boundary-work and the demarcation of science from non-science: strains and interests in professional ideologies of scientists. American Sociological Review 1983; 48: 781-95.

19. Grady K. Building capacity for anaesthesia in low resource settings. BJOG 2009; 116(Suppl 1): 15-7.

20. Moulton CA, Regehr G, Mylopoulos M, MacRae HM. Slowing down when you should: a new model of expert judgment. Acad Med 2007; 82: S109-16.

21. Norman GR, Rosenthal D, Brooks LR, Allen SW, Muzzin LJ. The development of expertise in dermatology. Arch Dermatol 1989; 125: 1063-8.

22. Norman GR, Coblentz CL, Brooks LR, Babcook CJ. Expertise in visual diagnosis: a review of the literature. Acad Med 1992; 67: S78-83.

23. Berbaum KS, Franken EA Jr, Dorfman DD, Lueben KR. Influence of clinical history on perception of abnormalities in pediatric radiographs. Acad Radiol 1994; 1: 217-23. 
24. Krupinski EA. Technology and perception in the 21st-century reading room. J Am Coll Radiol 2006; 3: 433-40.

25. Custers EJ. Long-term retention of basic science knowledge: a review study. Adv Health Sci Educ Theory Pract 2010; 15: 109-28.

26. Grunwald T, Corsbie-Massay C. Guidelines for cognitively efficient multimedia learning tools: educational strategies, cognitive load, and interface design. Acad Med 2006; 81: 213-23.

27. Mayer RE. Applying the science of learning to medical education. Med Educ 2010; 44: 543-9.

28. Regehr G, Norman GR. Issues in cognitive psychology: implications for professional education. Acad Med 1996; 71: 988-1001.

29. Eva $K W$. What every teacher needs to know about clinical reasoning. Med Educ 2005; 39: 98-106.

30. Wegwarth $O$, Gaissmaier W, Gigerenzer G. Smart strategies for doctors and doctors-in-training: heuristics in medicine. Med Educ 2009; 43: 721-8.

31. Charlin B, Boshuizen HP, Custers EJ, Feltovich PJ. Scripts and clinical reasoning. Med Educ 2007; 41: 1178-84.

32. Ericsson $K A$. Deliberate practice and the acquisition and maintenance of expert performance in medicine and related domains. Acad Med 2004; 79: S70-81.

33. Ericsson $K$, Charness $N$. Expert performance: its structure and acquisition. American Psychologist 1994; 49: 725-47.

34. Schmidt HG, Rikers RM. How expertise develops in medicine: knowledge encapsulation and illness script formation. Med Educ 2007; 41: 1133-9.

35. Butler AC, Karpicke JD, Roediger HL 3rd. The effect of type and timing of feedback on learning from multiple-choice tests. J Exp Psychol Appl 2007; 13: 273-81.

36. Twenge JM. Generational changes and their impact in the classroom: teaching Generation Me. Med Educ 2009; 43: 398-405.

37. Eva $K W$, Regehr $G$. Self-assessment in the health professions: a reformulation and research agenda. Acad Med 2005; 80: S46-54.

38. LeBlanc VR. The effects of acute stress on performance: implications for health professions education. Acad Med 2009; 84: S25-33.

39. Larsen DP, Butler AC, Roediger HL 3rd. Test-enhanced learning in medical education. Med Educ 2008; 42: 959-66.

40. Wood T. Assessment not only drives learning, it may also help learning. Med Educ 2009; 43: 5-6.

41. Kromann $C B$, Jensen $M L$, Ringsted $C$. The effect of testing on skills learning. Med Educ 2009; 43: 21-7.

42. Glavin R, Flin R. Review article: The influence of psychology and human factors on education in anesthesiology. Can J Anesth 2012; 59: this issue. DOI:10.1007/s12630-011-9634-z.

43. Schulz KF, Altman DG, Moher D, CONSORT Group. CONSORT 2010 statement: updated guidelines for reporting parallel group randomized trials. Ann Intern Med 2010; 152: 726-32.

44. Ahlberg G, Enochsson L, Gallagher AG, et al. Proficiency-based virtual reality training significantly reduces the error rate for residents during their first 10 laparoscopic cholecystectomies. Am J Surg 2007; 193: 797-804.

45. Jha V, Bekker HL, Duffy SR, Roberts TE. A systematic review of studies assessing and facilitating attitudes towards professionalism in medicine. Med Educ 2007; 41: 822-9.

46. Barbour RS. Making sense of focus groups. Med Educ 2005; 39: $742-50$.

47. DiCicco-Bloom B, Crabtree BF. The qualitative research interview. Med Educ 2006; 40: 314-21.

48. Atkinson P, Pugsley L. Making sense of ethnography and medical education. Med Educ 2005; 39: 228-34.

49. Pope $C$. Conducting ethnography in medical settings. Med Educ 2005; 39: 1180-7.
50. Kennedy TJ, Lingard LA. Making sense of grounded theory in medical education. Med Educ 2006; 40: 101-8.

51. Lingard L. Qualitative research in the RIME community: critical reflections and future directions. Acad Med 2007; 82: S129-30.

52. Bunniss $S$, Kelly DR. Research paradigms in medical education research. Med Educ 2010; 44: 358-66.

53. Kuper A, Reeves $S$, Levinson $W$. An introduction to reading and appraising qualitative research. BMJ 2008; 337: a288.

54. Pope $C$, Mays $N$. Critical reflections on the rise of qualitative research. BMJ 2009; 339: b3425.

55. Kuper A, Lingard L, Levinson W. Critically appraising qualitative research. BMJ 2008; 337: a1035.

56. Bligh J, Brice $J$. What is the value of good medical education research? Med Educ 2008; 42: 652-3.

57. Monrouxe LV, Rees CE. Picking up the gauntlet: constructing medical education as a social science. Med Educ 2009; 43: 196-8.

58. Bordage $G$. Moving the field forward: going beyond quantitative-qualitative. Acad Med 2007; 82: S126-8.

59. Schifferdecker KE, Reed VA. Using mixed methods research in medical education: basic guidelines for researchers. Med Educ 2009; 43: 637-44.

60. Wijeysundera DN, Feldman BM. Quality, not just quantity: the role of qualitative methods in anesthesia research. Can J Anesth 2008; 55: 670-3.

61. Shafer A. "It blew my mind": exploring the difficulties of anesthesia informed consent through narrative. Anesthesiology 2009; 110: 445-6.

62. Borgeat A, Brennan TJ, Eisenach JC, et al. 2009 in review: advancing medicine in anesthesiology. Anesthesiology 2009; 111: 1192-6.

63. Waisel DB, Lamiani G, Sandrock NJ, Pascucci R, Truog RD, Meyer EC. Anesthesiology trainees face ethical, practical and relational challenges in obtaining informed consent. Anesthesiology 2009; 110: 480-6.

64. Cook DA. One drop at a time: research to advance the science of simulation. Simul Healthc 2010; 5: 1-4.

65. Cook DA, Bordage G, Schmidt HG. Description, justification and clarification: a framework for classifying the purposes of research in medical education. Med Educ 2008; 42: 128-33.

66. Royal College of Anaesthetists (UK). The CCT in Anaesthetics IV: Competency Based Higher and Advanced Level (Specialty Training (ST) Years 5, 6 and 7) Training and Assessment. A manual for trainees and trainers. Interim edition: January 2007; Amendment 2: April 2009. Available from URL: http://www. rcoa.ac.uk/docs/CCTptiv.pdf (accessed May 2011).

67. Royal College of Anaesthetists (UK). The CCT in Anaesthetics III: Competency Based Intermediate Level (Specialty Training (ST) Years 3 and 4) Training and Assessment. A manual for trainees and trainers. Edition 1: January 2007; Amendment 1: April 2009. Available from URL: http://www.rcoa.ac.uk/docs/ CCTptiii.pdf (accessed May 2011).

68. Royal College of Anaesthetists (UK). The CCT in Anaesthetics II: Competency Based Basic Level (Specialty Training (ST) Years 1 and 2) Training and Assessment. A manual for trainees and trainers. Edition 1: January 2007; Amendment 2: April 2009. Available from URL: http://www.rcoa.ac.uk/index.asp? PageID=57 (accessed May 2011).

69. Royal College of Anaesthetists (UK). The CCT in Anaesthetics I: General Principles. A manual for trainees and trainers. Edition 1: January 2007; Amendment 2: April 2009. Available from URL: http://www.rcoa.ac.uk/docs/CCTparti.pdf (accessed May 2011).

70. Goldie J. AMEE education guide no. 29: evaluating educational programmes. Med Teach 2006; 28: 210-24. 
71. Hundert EM, Hafferty F, Christakis D. Characteristics of the informal curriculum and trainees' ethical choices. Acad Med 1996; 71: 624-42.

72. Hamstra SJ, Woodrow SI, Mangrulkar RS. Feeling pressure to stay late: socialisation and professional identity formation in graduate medical education. Med Educ 2008; 42: 7-9.

73. Tooke J. Aspiring to excellence: final report of the independent inquiry into modernising medical careers. London: MMC Inquiry 2008. Available from URL: http://www.mmcinquiry. org.uk/MMC_FINAL_REPORT_REVD_4jan.pdf (accessed May 2011).

74. Wong AK. Curriculum development in anesthesia: basic theoretical principles. Can J Anesth 2006; 53: 950-60.

75. Cumin D, Merry AF. Simulators for use in anaesthesia. Anaesthesia 2007; 62: 151-62.

76. McGaghie WC, Issenberg SB, Petrusa ER, Scalese RJ. A critical review of simulation-based medical education research: 2003-2009. Med Educ 2010; 44: 50-63.

77. Ziv A, Wolpe PR, Small SD, Glick S. Simulation-based medical education: an ethical imperative. Simul Healthc 2006; 1: 252-6.

78. Wong $G$, Greenhalgh T, Pawson R. Internet-based medical education: a realist review of what works, for whom and in what circumstances. BMC Med Educ 2010; 10: 12.

79. Hammick $M$, Freeth D, Koppel I, Reeves S, Barr H. A best evidence systematic review of interprofessional education: BEME Guide no. 9. Med Teach 2007; 29: 735-51.

80. Zwarenstein M, Goldman J, Reeves $S$. Interprofessional collaboration: effects of practice-based interventions on professional practice and healthcare outcomes. Cochrane Database Syst Rev 2009; (3): CD000072.

81. Spencer $J$. ABC of learning and teaching in medicine: learning and teaching in the clinical environment. BMJ 2003; 326: 591-4.

82. Halsted $W$. The training of the surgeon. Bullet Johns Hopkins Hosp 1904; 15: 267-76.

83. Frank JR, Snell LS, Cate OT, et al. Competency-based medical education: theory to practice. Med Teach 2010; 32: 638-45.

84. ACGME Board. Common Program Requirements: General Competencies. Approved by the ACGME Board February 13, 2007. Available from URL: http://www.acgme.org/outcome/ comp/generalcompetenciesstandards21307.pdf (accessed May 2011).

85. Tetzlaff JE. Assessment of competency in anesthesiology. Anesthesiology 2007; 106: 812-25.

86. Snell LS, Frank JR. Competencies, the tea bag model, and the end of time. Med Teach 2010; 32: 629-30.

87. Brooks MA. Medical education and the tyranny of competency. Perspect Biol Med 2009; 52: 90-102.

88. Lurie SJ, Mooney CJ, Lyness JM. Measurement of the general competencies of the accreditation council for graduate medical education: a systematic review. Acad Med 2009; 84: 301-9.

89. Jaques $D$. ABC of learning and teaching in medicine: teaching small groups. BMJ 2003; 326: 492-4.

90. Edmunds S, Brown G. Effective small group learning: AMEE Guide No. 48. Med Teach 2010; 32: 715-26.

91. Cantillon P. ABC of learning and teaching in medicine: teaching large groups. BMJ 2003; 326: 437.

92. Brown G, Manogue M. AMEE medical education guide no. 22: refreshing lecturing: a guide for lecturers. Med Teach 2001; 23 : 231-44.

93. Jones $R W$, Morris $R W$. Facilitating learning in the operating theatre and intensive care unit. Anaesth Intensive Care 2006; 34: 758-64.

94. Polanyi M, Sen A. The Tacit Dimension. Chicago: University of Chicago Press; 2009.

95. Smith A, Goodwin D, Mort M, Pope C. Expertise in practice: an ethnographic study exploring acquisition and use of knowledge in anaesthesia. Br J Anaesth 2003; 91: 319-28.
96. Kulcsar Z, Aboulafia A, Hall T, Shorten GD. Determinants of learning to perform spinal anaesthesia: a pilot study. Eur $\mathbf{J}$ Anaesthesiol 2008; 25: 1026-31.

97. Smith A, Pope C, Goodwin D, Mort M. What defines expertise in regional anaesthesia? An observational analysis of practice. Br J Anaesth 2006; 97: 401-7.

98. Cleave-Hogg D, Benedict C. Characteristics of good anaesthesia teachers. Can J Anaesth 1997; 44: 587-91.

99. Sutkin G, Wagner E, Harris I, Schiffer R. What makes a good clinical teacher in medicine? A review of the literature. Acad Med 2008; 83: 452-66.

100. Ramani $S$. Twelve tips to promote excellence in medical teaching. Med Teach 2006; 28: 19-23.

101. Harden RM. Trends and the future of postgraduate medical education. Emerg Med J 2006; 23: 798-802.

102. Grant $J$. Learning needs assessment: assessing the need. BMJ 2002; 324: 156-9.

103. Cantillon P, Sargeant J. Giving feedback in clinical settings. BMJ 2008; 337: a1961.

104. Archer JC. State of the science in health professional education: effective feedback. Med Educ 2010; 44: 101-8.

105. Baker $K$. Clinical teaching improves with resident evaluation and feedback. Anesthesiology 2010; 113: 693-703.

106. Cook DA, Triola MM. Virtual patients: a critical literature review and proposed next steps. Med Educ 2009; 43: 303-11.

107. Castanelli DJ. The rise of simulation in technical skills teaching and the implications for training novices in anaesthesia. Anaesth Intensive Care 2009; 37: 903-10.

108. Doyle DJ. Web-based education in anesthesiology: a critical overview. Curr Opin Anaesthesiol 2008; 21: 766-71.

109. Lane $C$, Rollnick $S$. The use of simulated patients and role-play in communication skills training: a review of the literature to August 2005. Patient Educ Couns 2007; 67: 13-20.

110. Beard L, Wilson K, Morra D, Keelan J. A survey of healthrelated activities on second life. J Med Internet Res 2009; 11: e17.

111. Gaba DM. Improving anesthesiologists' performance by simulating reality. Anesthesiology 1992; 76: 491-4.

112. Hall RE, Plant JR, Bands CJ, Wall AR, Kang J, Hall CA. Human patient simulation is effective for teaching paramedic students endotracheal intubation. Acad Emerg Med 2005; 12: 850-5.

113. Barsuk JH, McGaghie WC, Cohen ER, O'Leary KJ, Wayne DB. Simulation-based mastery learning reduces complications during central venous catheter insertion in a medical intensive care unit. Crit Care Med 2009; 37: 2697-701.

114. Wayne DB, Didwania A, Feinglass J, Fudala MJ, Barsuk JH, McGaghie WC. Simulation-based education improves quality of care during cardiac arrest team responses at an academic teaching hospital: a case-control study. Chest 2008; 133: 56-61.

115. Bruppacher HR, Alam SK, LeBlanc VR, et al. Simulation-based training improves physicians' performance in patient care in high-stakes clinical setting of cardiac surgery. Anesthesiology 2010; 112: 985-92.

116. Issenberg SB, McGaghie WC, Petrusa ER, Gordon DL, Scalese $R J$. Features and uses of high-fidelity medical simulations that lead to effective learning: a BEME systematic review. Med Teach 2005; 27: 10-28.

117. Epstein RM. Assessment in medical education. N Engl J Med 2007; 356: 387-96.

118. Miller GE. The assessment of clinical skills/competence/performance. Acad Med 1990; 65: S63-7.

119. Savoldelli GL, Naik VN, Joo HS, et al. Evaluation of patient simulator performance as an adjunct to the oral examination for senior anesthesia residents. Anesthesiology 2006; 104: 475-81.

120. Berkenstadt H, Ziv A, Gafni N, Sidi A. The validation process of incorporating simulation-based accreditation into the 
anesthesiology Israeli national board exams. Isr Med Assoc J 2006; 8: 728-33.

121. van der Vleuten $C P$. The assessment of professional competence: developments, research and practical implications. Adv Health Sci Educ 1996; 1: 41-67.

122. Bould MD, Crabtree NA, Naik VN. Assessment of procedural skills in anaesthesia. Br J Anaesth 2009; 103: 472-83.

123. Flin R, Patey $R$, Glavin R, Maran $N$. Anaesthetists' non-technical skills. Br J Anaesth 2010; 105: 38-44.

124. Mays N, Pope C. Qualitative research in health care. Assessing quality in qualitative research. BMJ 2000; 320: 50-2.

125. van der Vleuten $C P$, Schuwirth $L W$. Assessing professional competence: from methods to programmes. Med Educ 2005; 39: 309-17.

126. ACGME. ACGME Competencies: Suggested Best Methods for Evaluation. Available from URL: http://www.acgme.org/ Outcome/assess/ToolTable.pdf (accessed May 2011).

127. Wass V, Van der Vleuten C, Shatzer J, Jones R. Assessment of clinical competence. The Lancet 2001; 357: 945-9.

128. Beattie DS. Expanding the view of scholarship: introduction. Acad Med 2000; 75: 871-6.

129. Fioratou E, Flin $R$, Glavin R, Patey $R$. Beyond monitoring: distributed situation awareness in anaesthesia. $\mathrm{Br} \mathrm{J}$ Anaesth 2010; 105: 83-90.
130. Waring J, Harrison $S$, McDonald $R$. A culture of safety or coping? Ritualistic behaviours in the operating theatre. J Health Serv Res Policy 2007; 12: 3-9.

131. Iedema R, Jorm C, Lum M. Affect is central to patient safety: the horror stories of young anaesthetists. Soc Sci Med 2009; 69: 1750-6.

132. Wulf $G$, Shea $C$, Lewthwaite $R$. Motor skill learning and performance: a review of influential factors. Med Educ 2010; 44: 75-84.

133. Larsson J, Holmstrom I, Rosenqvist U. Professional artist, good Samaritan, servant and co-ordinator: four ways of understanding the anaesthetist's work. Acta Anaesthesiol Scand 2003; 47: 787-93.

134. Weller JM, Jones A, Merry AF, Jolly B, Saunders D. Investigation of trainee and specialist reactions to the mini-Clinical Evaluation Exercise in anaesthesia: implications for implementation. Br J Anaesth 2009; 103: 524-30.

135. Prideaux D. ABC of learning and teaching in medicine. Curriculum design. BMJ 2003; 326: 268-70. 